\title{
The Effect of Topical Application of Mother Breast Milk Versus Distilled Water and Alcohol on Separation Time of Umbilical Cord Stump Among Neonates
}

\author{
Abeer Abd El-Aziz Madian ${ }^{1 *}$ and Marwa Mohamed Ahmed Ouda ${ }^{2}$ \\ ${ }^{1}$ Department of Community Health Nursing, Damanhour University, Egypt \\ ${ }^{2}$ Department of Pediatric Nursing, Damanhour University, Egypt, College of Applied Medical science/ Nursing, Jouf University, KSA
}

*Corresponding author: Abeer Abd El-Aziz Madian, Department of Community Health Nursing, Faculty of Nursing, Damanhour University, Egypt, Email: abmadian@hotmail.com
Received Date: February 26, 2019

Published Date: March 19, 2019

\section{Abstract}

Umbilical cord infections donate to the increased morbidity and mortality in neonates of developing countries, where neonates are exposed to unhygienic practices. The aim of the study was to monitor the effect of topical application of breast milk compared to distilled water and alcohol on separation time of umbilical cord stump among neonates.

Methods: This research was a randomized clinical trial done on 90 mature neonates that were placed randomly in the three groups of study. The umbilical cord separation time was compared in the three groups.

Results: Mean time of cord separation in human milk application group (6.72 \pm 1.66$)$ was significantly shorter than distilled water and alcohol groups. Moreover, the bleeding continuation after separation (day) was significantly shorter $(p<0.001)$ among breast milk group than distilled water group and majority of neonates among the 3 groups didn't have any signs of umbilical cord infection.

Conclusion: Topical application of human milk on the remaining part of the cord reduces the cord separation time and it can be used as an easy and cheap way for cord care.

Keywords: Mother breast milk; Distilled water; Alcohol; Separation; Umbilical cord; Neonates

\section{Introduction}

The umbilical cord is a sole tissue containing two arteries and one vein enclosed by a connective tissue called Wharton's Jelly which is thin and mucoid in nature. After delivery of the neonate and placental separation, the umbilical cord is cut using a sterile technique and the neonate must make the essential transition to extra-uterine life. The umbilical cord must be cut and clamped in order to retain the umbilical vessels occluded to prevent bleeding [1].

Hereafter, the umbilical cord is the life giver for the fetus but at the same time it could be a life destroyer of the neonates by acquiring infection through the vessels into the neonate's blood stream. So, corrected umbilical cord care is important to prevent infections in neonatal period [2]. Despite the fact that there is a general agreement about the 'clean' technique for cutting the cord using a sterile cutting instrument (blade or scissors) and clean hands to avoid infection, there is less agreement on what is the best care of the cord stump [3].

Omphalitis is one of the ways by which severe neonatal infections such as sepsis and tetanus can occur. The signs like redness, edema or discharge at the umbilicus may cause anxiety to mothers. It may not be very severe to be treated with antibiotics Although the prevalence of omphalitis in developed countries has reduced with umbilical cord care, it is still considered as an imperative cause of infant mortality in developing countries [4]. The World Health Organization (WHO) guesses that 4 million children die each year during the neonatal period, with most of deaths occurring in developing countries [5].

Consequently, cord infections can be prevented in most cases through identification of best cord care practices which offer an alternative approach to widespread potentially harmful traditional 
practices. Instances of such damaging practices consist of the use of traditional herbs mixed with cooking oil or application of ash, fluid from pumpkin flowers, powder ground from local trees, cow dung, ghee and saliva [6]. In addition, different antiseptics such as alcohol, chlorhexidine, triple dye and salicylic sugar powder can be used for umbilical cord disinfection. However, it was discovered factors that can delay the process of cord stump separation are the application of antiseptics, infection and caesarean section [7-9].

Based on predominant complications of different caring methods for umbilical cord the World Health Organization (WHO) recommended keeping the umbilical cord dry. Data reveled from recent researches regarding this method has been significantly supported. However, there are a lot of discrepancies whether this method can be considered as the best method for caring umbilical cord [10]. Evidence based practices showed that neonates who used human milk had lower umbilical extraction time compared to those who used antiseptic solutions.

Breast milk is a deep yellow fluid contains many types of cells, hormones, and antibodies that protect neonates from infections. Moreover, it is available, easy to use, ready sterile and cost less method for cord care [11]. Hospitalization charge of umbilical cord treatment fluctuates by application used and length of hospital stay. Henceforward, it is significant to find low-cost alternative cord care; e.g. breast milk especially in low socio-economic countries. This helps in simpler cost-effective treatment [12].

\section{Significance of the Study}

The best way to treat the umbilical cord after birth is a confrontational issue especially in developing countries which dared by many local practices and beliefs. Efforts to recognize and implement realistic and effective community-based interventions for umbilical cord care may diminish the large load of infection related neonatal mortality in developing countries. This is emphasized by desires from nurses to improve umbilical cord care according to updating practice. A better accepting of such practices is vital issue for researchers to offer new effective strategies to lessen cord infections in the millions of neonates born each year [13].

\section{Aim of study}

In view of that, the present study was fulfilled to monitor the effect of topical application of mother breast milk versus distilled water and alcohol on separation time of umbilical cord stump among neonates.

\section{Hypothesis of the Study}

Neonates who had topical mother breast milk application exhibited quickly separation time of umbilical cord stump than those who had either distilled water or alcohol.

\section{Material and Methods}

\section{Research design}

Randomized clinical trial research design was approved to demeanor this study.

\section{Setting}

The study was accompanied at two settings: first one was Obstetric and Gynecological ward which is affiliated to the National Medical Institute of Damanhour City, Egypt. The second was neonates' homes.

\section{Subjects}

Neonates delivered by normal vaginal deliveries or cesarean section were selected randomly from Maternity ward at the National Medical Institute of Damanhour City- Egypt according to the following inclusion criteria:

1. Healthy full-term neonates from (38-42 weeks of gestation).

2. Normal birth weight from (2.500 to 4000) grams.

3. Absence of congenital anomalies.

4. Roomed-in with their mothers and breast fed.

5. Apgar score at first and fifth minute equal 7 and more.

6. Not admitted to neonatal intensive care unit.

7. Had no maternal complications.

\section{Sample size}

Based on the monthly ratio of delivered mothers who admitted to Maternity ward (500) women, the sample size ( $\mathrm{N}=90)$ was calculated taking $15 \%$ proportion of $6 \%$ margin error and $95 \%$ confidence level.

\section{Sampling technique}

1. The study subjects were designated after identifying the list of admission rate per setting daily and according to the previously mentioned inclusion criteria. The samples were owed randomly and equally alienated into three study groups.

2. Study group (1) included 30 neonates: received topical application of mother milk to the umbilical cord stump at three hours after birth then every 8 hours ( 3 times per day) to 2 days after the umbilical cord separation and during diaper care.

3. Study group (2) comprised 30 neonates who practiced distilled water.

4. Study group (3) receives alcohol solution, by sterile gauze, to the umbilical stump from three hours after birth and continued every 12 hours until two days after umbilical cord separation and during diaper care.

\section{Tools of Data Collection}

Three tools were used and filled by the researchers to collect data. Content of tools was determined through an intensive review of literatures and researches concerning cord care.

\section{Tool “1 “Structured interview schedule:}

It was conducted to collect data related to the mothers and their neonates. This tool included three parts: 
Part (I)

Socio-demographic characteristics; it consists of 7 items: maternal age (years), mother's educational status, residence, mother's employment status, type of family, crowding index and family income. The Socioeconomic level was resolute according to the total socioeconomic score settled by Fahmy and El- Sherbini [14]. The maximum score was 34 points and it was classified into three levels as follows:

High social level $\geq 75 \%$ " $\geq 25$ " points.

Middle social level 50 - < $75 \%$ "17 - <25" points.

Low social level $<50 \%$ " $<17$ " points.

Part (II): includes data related to parity, route of delivery and data related to the neonate as gender and birth weight.

Part (III): includes knowledge of mothers regarding cord care and source of their knowledge. It entails questions as, meaning of standard cord care, solution used for cleaning cord, umbilical cord separation time, umbilical cord infection signs and umbilical cord care benefits. The knowledge correct response was scored 1 and the incorrect or don't know scored 0 ,these scores were converted into a percent score, the mothers' knowledge was considered satisfactory if percent score was $50 \%$ or more and unsatisfactory if less $50 \%$.

\section{Tool "2 "cord swab bacteriological examination tool}

It was done for the three groups of study by a trained technologist who was unaware of the classification of the neonates .First swab was taken immediately after delivery of the neonates and second swab taken after 3 days from delivery and sent to the bacteriology laboratory if there was no bacterial growth, he followed it for a week after to confirm the result. When there was a bacterial growth the technologist followed this bacterial growth up to two weeks.

\section{Tool " 3 "follow up schedule checklist for observing signs of cord healing and separation}

This checklist was developed by the researchers and filled by them to check the presence or not the signs of cord infection as (redness around the area, a foul odor, discharge, or discomfort when touch the area around the umbilical cord) until cord detachment occur.

\section{Methodology}

a. An official letter from the Faculty of Nursing, Damanhour University was obtained and forwarded to the National Medical Institute Directorate to take his permission to conduct the study after explaining its purpose.

b. Validity: Tools were validated by submitting them to 3 experts at the same field and the modifications were incorporated in the final preparation of the tool.

c. Reliability was tested of tools 1 and 3 by cronbach alpha test. Its result was 0.721 which specifies an accepted reliability of the tool.

d. The study subjects were selected in keeping with the predetermined inclusion criteria. e. Pilot study was carried out with the intention of ensure the clarity of the tool. It was carried out on 9 neonates from Maternity ward at the National Medical Institute which were not included in the study sample.

f. Henceforth, 90 neonates were randomly allocated and divided into three groups.

\section{Data collection process}

All mothers had been fully informed about the research and consented after explaining the purpose of the study to gain their cooperation for participation in the research. The researchers ensure safety and prevention of the potential risk by enforced good hand washing by mothers prior to implementation of both methods of cord care. Researchers inquired questions in a simple Arabic language and note down the answers in the structure interview tool.

\section{Data collection was carried out through four phases:}
a. Interviewing
b. Assessment
c. Implementation and
d. Evaluation

Interviewing phase: Initial visits, the researchers met all postpartum mothers at Maternity ward. Then according to the pre-determined inclusion criteria of neonates were recruited, apportioned for three groups and their mothers interviewed individually. The interview continued about one hour for each mother.

Assessment phase: In this phase, neonates were examined firstly by the researchers to collect the baseline data related to cord status before the intervention of both groups. These assessments took about 20 minutes for each neonate.

Implementation phase: At the beginning of the study, the researchers offered the best evidence practice about the way of cord care and gave mothers general instructions during a session for one hour after birth about gently clean the umbilical cord stump and the surrounding skin every 12 hours and during diaper changes, retain neonate's diaper folded below the umbilical cord stump to keep the stump exposed to air. It also helps avoid diaper contents, such as urine, from irritating and contaminating the stump. Instruct mothers that umbilical cord stump will change from yellowish green to brown to black as it dries out and eventually falls off, usually between 1 and 2 weeks after birth. It is vital to keep the umbilical cord stump and surrounding skin clean and dry. After the stump falls off continue cleaning around the navel at least two days until the navel has completely restored (after stump falls off). Moreover, sponge bath is superior during the healing process. Regarding the mothers who bathing their neonates in sink, they were taught to keep the umbilical cord stump above the water level until the stump falls off. Everyday mothers notice that the cord will get smaller and pull away from the center of the belly button. Mothers also, informed to avoid pull the cord off. When the stump falls off, mother can bath the neonate in a neonate's tub or sink. These basic care 
help to prevent the occurrence of infection and help the umbilical cord stump to fall off and the navel to heal more quickly. All mothers instructed before discharge from the hospital concerning: method of cord care, and when to call the researchers to make referral to the pediatrician (if the neonate develops a fever or if the umbilical area appears red and swollen around the cord; crying when the mother touches the cord or skin around it; continues to bleed; oozes yellowish pus; and produces a foul-smelling discharge). It is normal to notice oozing of fluid for one or two days after the stump fell off. After general instructions each mother was interviewed for 20 minutes to determine her perception about cord care best practice. Explanation for the mothers in both groups was done to get their agreement.

Technique of procedure: three groups were constituted 90 neonates; each neonate was randomly assigned into the 3 groups.

Group 1: who received cord care with topical application of mothers' breast milk, mothers instructed to squeeze foremilk drops (before lactation) on the remaining part of the cord about 4-6 drops and its cut edge and let the milk get completely dry and the milk not washed off later. The application of the care beginning 3 hours after birth to ensure the mother became alert after delivery. The researchers' asked the mother to apply milk drops 3times per day and during diaper care until cord separation and 2 days after.

Group 2: who received care by distilled water; the researchers were taught the mothers to clean the umbilical cord by water then allowing it to complete dryness 3times per day and during diaper care until cord separation and 2 days after.

Group 3: who received application of alcohol, the researchers' asked the mother to apply by a sterile gauze or swab of alcohol to the umbilical stump from 3 hours after birth and continued every 12 hours and during diaper care until 2 days after umbilical cord separation.

Evaluation phase: Outcome was measured in terms of the presence or absence of omphalitis and the number of days elapsed before cord separation. In order to make sure of the presence of the microorganisms, cultures of the cord stump were collected using sterile swabs, first swab taken (immediately after delivery) of the neonates and second swab taken (after 3 days) from delivery. Samples were taken to the laboratory for analysis by the microbiologist. Mothers in three groups received forms to record the exact time of mothers' milk or alcohol application or distilled water during the day. Moreover, the mothers in three groups were asked to daily follow up for signs of cord infection; researchers follow up by telephone calls and during visit at home. In order to make sure the presence of the infection, researchers visited neonates within the first three hours after birth at hospital and days 3,7 and 2 days after umbilical cord separation at home.

Data were collected over a period of 9 months, starting from the beginning of September 2017 till the end of June 2018. The average number of interviewee 2-3 neonate neonates /week for 9 months).

\section{Statistical Analysis}

Data was investigated by means of PC with Statistical Package for Social Sciences (SPSS) version 20.0.

The following statistical measures were used:

1. Number and percentage: used for describing and summarizing qualitative data.

2. Arithmetic means and Standard deviation (SD): castoff as measures of central tendency and dispersion respectively to condense quantitative data.

3. Chi-square: used for comparison of qualitative variables between the studied groups.

4. T-test was used to liken between sample means for quantitative data with normal distribution (pre-post).

5. ANOVA test used to compare the means of three groups on the dependent variable.

6. Graphical presentation: were done for data visualization by using Microsoft Excel.

\section{Ethical Consideration}

For each enrolled subject the following issues were considered: written consent was obtained. Privacy was maintained during process of data collection. Confidentiality and anonymity of subjects were guaranteed. Permission from ethical committee in faculty of nursing was obtained.

\section{Results}

Table 1: Mothers' distribution along with their socio demographic characteristics.

\begin{tabular}{|c|c|c|c|c|c|c|c|}
\hline \multirow[t]{2}{*}{ Characteristics } & \multicolumn{2}{|c|}{$\begin{array}{c}\text { Group } 1 \\
\text { (Using Breast Milk) } \\
\mathbf{n}=\mathbf{3 0}\end{array}$} & \multicolumn{2}{|c|}{$\begin{array}{c}\text { Group } 2 \\
\text { (Using Distilled Water) } \\
\mathbf{n}=\mathbf{3 0}\end{array}$} & \multicolumn{2}{|c|}{$\begin{array}{c}\text { Group } 3 \\
\text { (Using Alcohol) } \\
\quad \mathbf{n}=\mathbf{3 0}\end{array}$} & \multirow{2}{*}{$\begin{array}{c}\text { Test } \\
\text { p-value }\end{array}$} \\
\hline & No & $\%$ & No & $\%$ & No & $\%$ & \\
\hline $\begin{array}{c}\text { Maternal age (years) } \\
\quad<25 \text { years } \\
\geq 25 \text { years }\end{array}$ & $\begin{array}{l}10 \\
20\end{array}$ & $\begin{array}{l}33.3 \\
66.7\end{array}$ & $\begin{array}{l}12 \\
18\end{array}$ & $\begin{array}{l}40.0 \\
60.0\end{array}$ & $\begin{array}{l}11 \\
19\end{array}$ & $\begin{array}{l}36.7 \\
63.3\end{array}$ & \multirow{3}{*}{$\begin{array}{l}X 2=0.96 \\
P=0.533\end{array}$} \\
\hline Min-Max & \multicolumn{2}{|c|}{$22.0-33.0$} & \multicolumn{2}{|c|}{$21.0-31.0$} & \multicolumn{2}{|c|}{$22.0-34.0$} & \\
\hline Mean +SD & \multicolumn{2}{|c|}{$27.53 \pm 4.61$} & \multicolumn{2}{|c|}{$26.44 \pm 4.11$} & \multicolumn{2}{|c|}{$27.11 \pm 4.2$} & \\
\hline
\end{tabular}




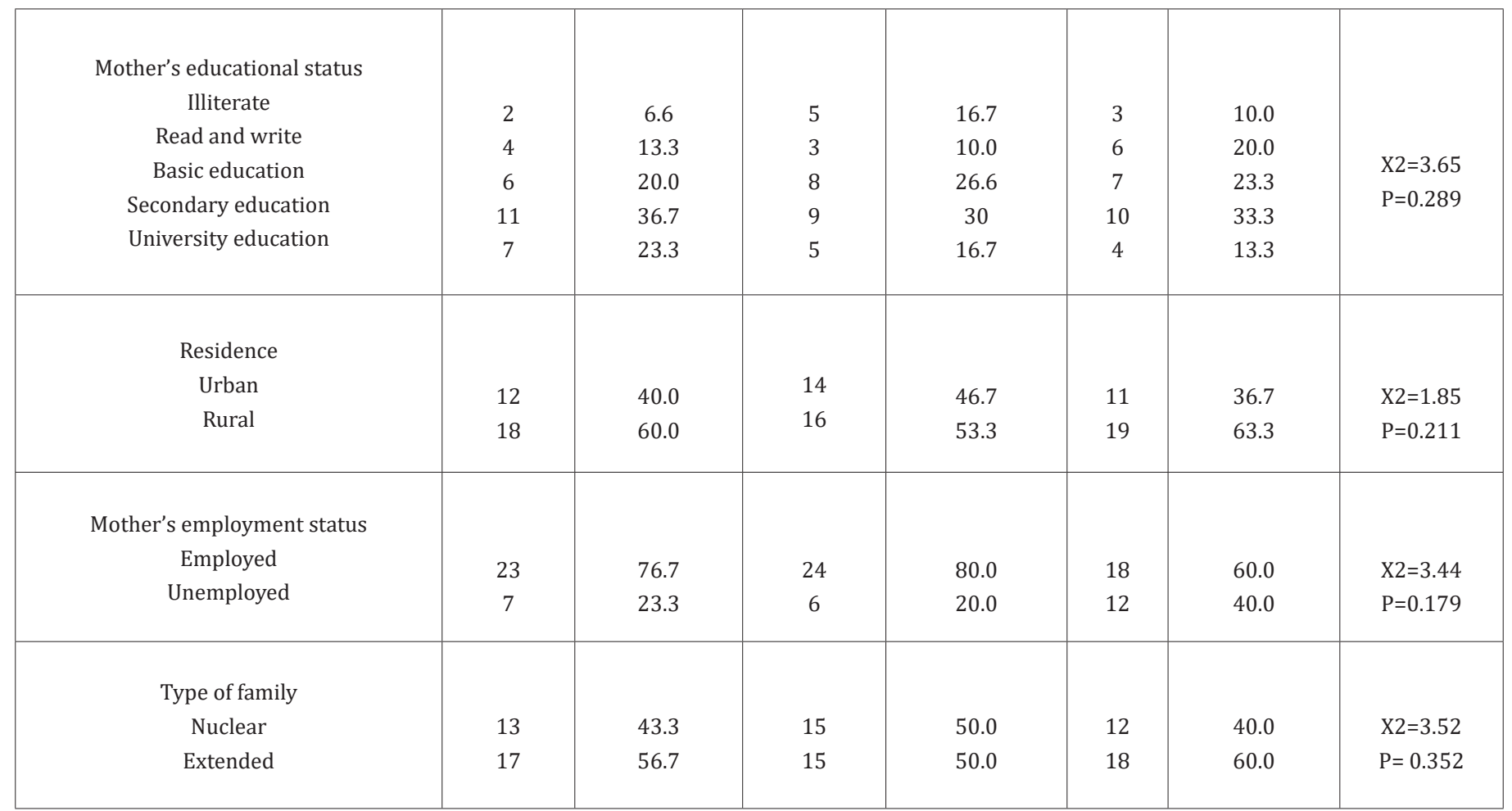

$\mathrm{X}^{2}$ : Chi-Square test ${ }^{*}$; Statistically significant at $\mathrm{p} \leq 0.05$.

Table (I) Illustrates mothers' distribution along with their socio demographic characteristics. It was clear that, the three studied groups were homogeneous in their characteristics .Mothers' age ranged between 22-33years with a mean age of $27.53 \pm 4.61$ for group 1, while in group 2 were ranged from 21-31 years with a mean age of $26.44 \pm 4$.11years and in group 3 ranged from 22-34 years with a mean age of $27.11 \pm 4.2$. No statistically significant difference was observed among three groups $\left(\mathrm{X}^{2}=0.96, \mathrm{P}=0.533\right)$. The highest percent (36.7\%) of mothers in group 1 had secondary education compared to less than one third (30.0\%) and exactly on third (33.3\%) among mothers in group 2 and 3 respectively. No statistically significant difference was found among groups $\left(\mathrm{X}^{2}=3.65\right.$, $\mathrm{p}=0.289$ ). Additionally, $60 \%, 53.3 \%$ and $63.3 \%$ of mothers in the 3 groups of study were rural residence even though $56.7 \%, 50 \%$ and $60 \%$ of mothers live in extended family, respectively. The highest percent $76.7 \%, 80 \%$, and $60 \%$ of mothers among three groups were working, respectively. No statistically significant difference was found among groups of study $\left(\mathrm{X}^{2}=3.44, \mathrm{P}=0.179\right)$.

Figure 1 discloses that highest percent of 3 groups had low socioeconomic status (57\%, 51.5\% \& $43.1 \%$ respectively), whereas $32.1 \%, 36.5 \%$ and $42.3 \%$ of mothers of group 1,group 2 and group 3 respectively had middle socioeconomic status.

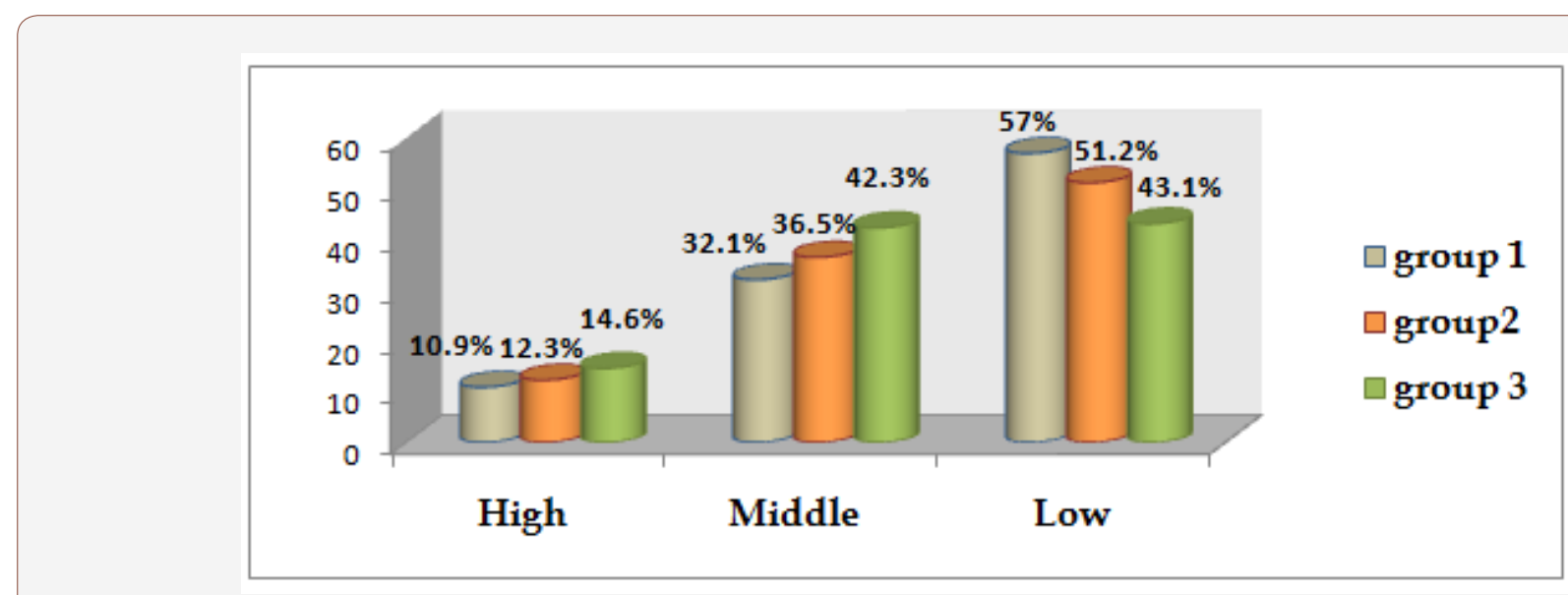

Figure 1: Socio socioeconomic level among the mothers of study subjects.

Table 2 proves that the highest percent of mothers at study groups were multipara 70\%, $60 \% \& 53.3 \%$ respectively. The neonates' birth weight ranged from 2.950-3.850 Kg with a mean weight of $3.221 \pm 0.450$ for group 1 where in group 2 were ranged from 2.650-3.900 $\mathrm{Kg}$ with a mean weight of $3.150 \pm 0.86 \mathrm{Kg}$. Furthermore, in group 3 the neonates' weight ranged from 2.890$3.750 \mathrm{Kg}$ with a mean weight of $3.250 \pm 0.91$. No statistically significant difference was found among groups $(\mathrm{t}=0.98, \mathrm{P}=0.421)$. 
Table 2: Mothers distribution along with their obstetric profile and neonates' characteristics.

\begin{tabular}{|c|c|c|c|c|c|c|}
\hline \multirow[t]{2}{*}{ Characteristics } & \multicolumn{2}{|c|}{$\begin{array}{c}\text { Group (Using Breast } \\
\text { Milk) } n=30\end{array}$} & \multicolumn{2}{|c|}{$\begin{array}{c}\text { Group } 2 \text { (Using Distilled } \\
\text { Water) } n=30\end{array}$} & \multirow{2}{*}{$\begin{array}{c}\text { Group } 3 \text { (Using Alcohol) } n=30 \\
\text { No }\end{array}$} & \multirow{2}{*}{$\begin{array}{c}\text { Test } \\
\text { P-value }\end{array}$} \\
\hline & No & $\%$ & No & $\%$ & & \\
\hline $\begin{array}{l}\text { Parity } \\
\text { Primi para } \\
\text { Multi para }\end{array}$ & $\begin{array}{c}9 \\
21\end{array}$ & $\begin{array}{l}30 \\
70\end{array}$ & $\begin{array}{l}12 \\
18\end{array}$ & $\begin{array}{l}40 \\
60 \\
\end{array}$ & $\begin{array}{l}14 \\
16\end{array}$ & \multirow{2}{*}{$\begin{aligned} \mathrm{X} 2 & =7.2111 \\
\mathrm{p} & =0.302\end{aligned}$} \\
\hline $\begin{array}{l}\text { Route of delivery } \\
\text { Vaginal delivery } \\
\text { Cesarean section }\end{array}$ & $\begin{array}{c}6 \\
24\end{array}$ & $\begin{array}{c}20 \\
8\end{array}$ & $\begin{array}{c}7 \\
23 \\
\end{array}$ & $\begin{array}{l}23.3 \\
76.7\end{array}$ & $\begin{array}{c}4 \\
26 \\
\end{array}$ & \\
\hline $\begin{array}{l}\text { Neonate's gender } \\
\text { Boys } \\
\text { Girls }\end{array}$ & $\begin{array}{l}16 \\
14\end{array}$ & $\begin{array}{l}53.3 \\
46.7\end{array}$ & $\begin{array}{l}12 \\
18\end{array}$ & $\begin{array}{l}40.0 \\
60.0 \\
\end{array}$ & $\begin{array}{l}14 \\
16\end{array}$ & $\begin{array}{l}X 2=1.07 \\
p=0.585\end{array}$ \\
\hline \multicolumn{6}{|c|}{ Birth weight (Kg) } & \multirow{3}{*}{$\begin{array}{c}\text { t-test }=0.98 \\
p=0.421\end{array}$} \\
\hline Min-Max & \multicolumn{2}{|c|}{$2.950-3.850$} & \multicolumn{2}{|c|}{$2.650-3.900$} & $2.890-3.750$ & \\
\hline Mean \pm SD & \multicolumn{2}{|c|}{$3.221 \pm 0.450$} & \multicolumn{2}{|c|}{$3.150 \pm 0.86$} & $3.250 \pm 0.91$ & \\
\hline
\end{tabular}

X2: Chi-Square test ${ }^{\star}$; Statistically significant at $p \leq 0.05$.

Figure 2 spectacles knowledge percent level score about cord care among mothers in 3 groups of sample; the figure reveals that about one third (38.7\%, $29.7 \%$ \& 31.4\%) of the mothers in study

groups respectively had satisfactory level of knowledge about cord care.

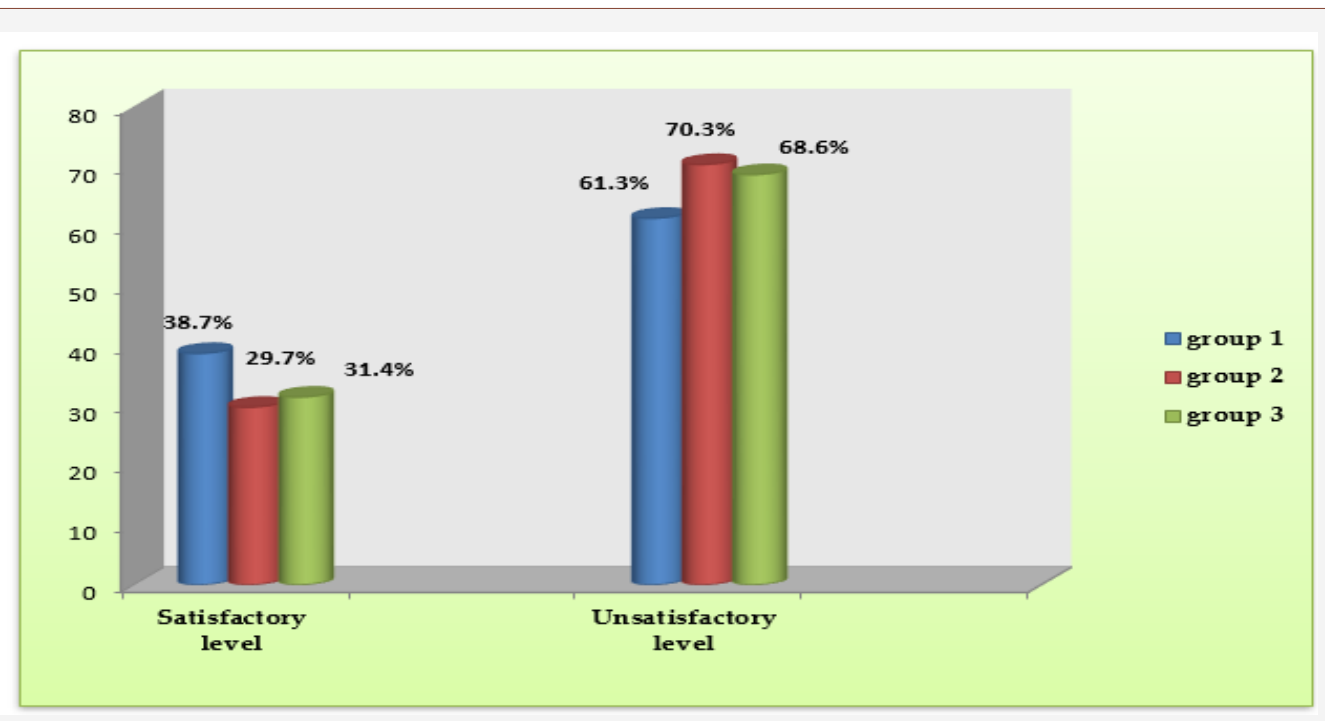

Figure 2: Knowledge percent score about cord care among the mothers.

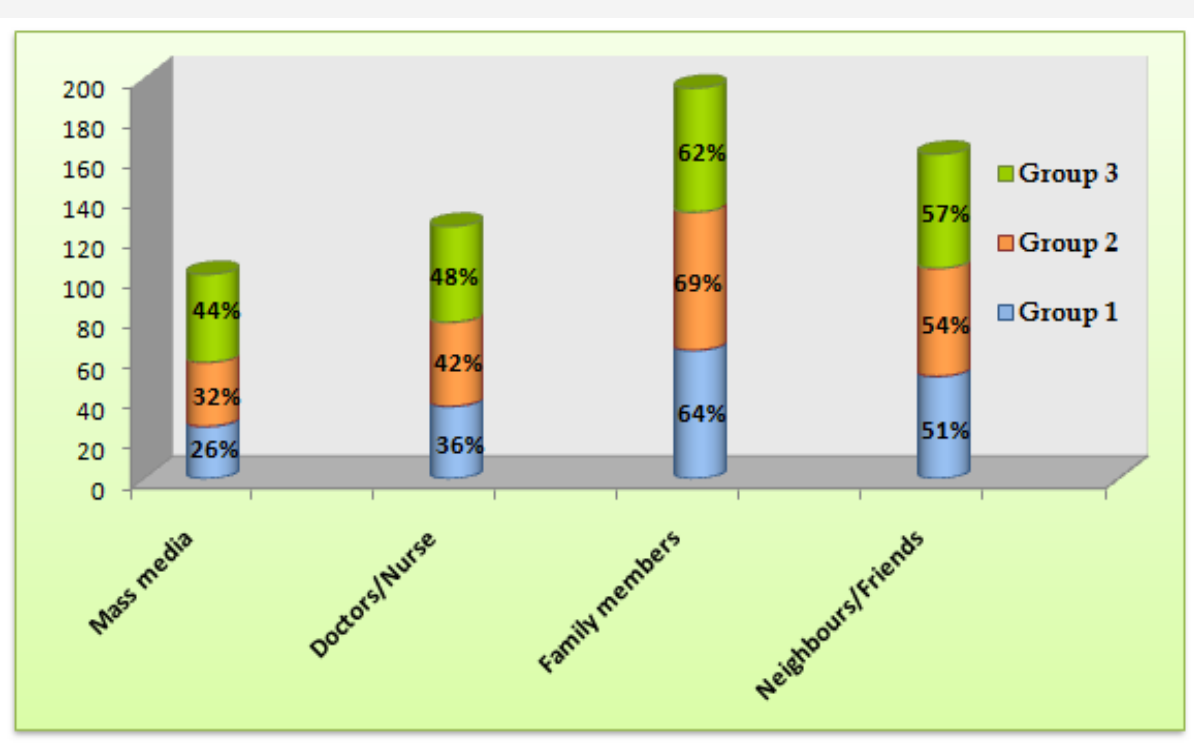

Figure 3: Source of knowledge about cord care among the mothers. 
Figure 3 pageants the mothers 'sources of knowledge about cord care, the figure demonstrates that in excess of two thirds $(64 \%, 69 \% \& 62 \%)$ of the mothers in study groups respectively, obtained their knowledge from family members. However, more than half $51 \%, 54 \% \& 57 \%$ of them obtained their knowledge from neighbors and friends, respectively.

Table 3: Cord separation time per days among the 3 groups of the study.

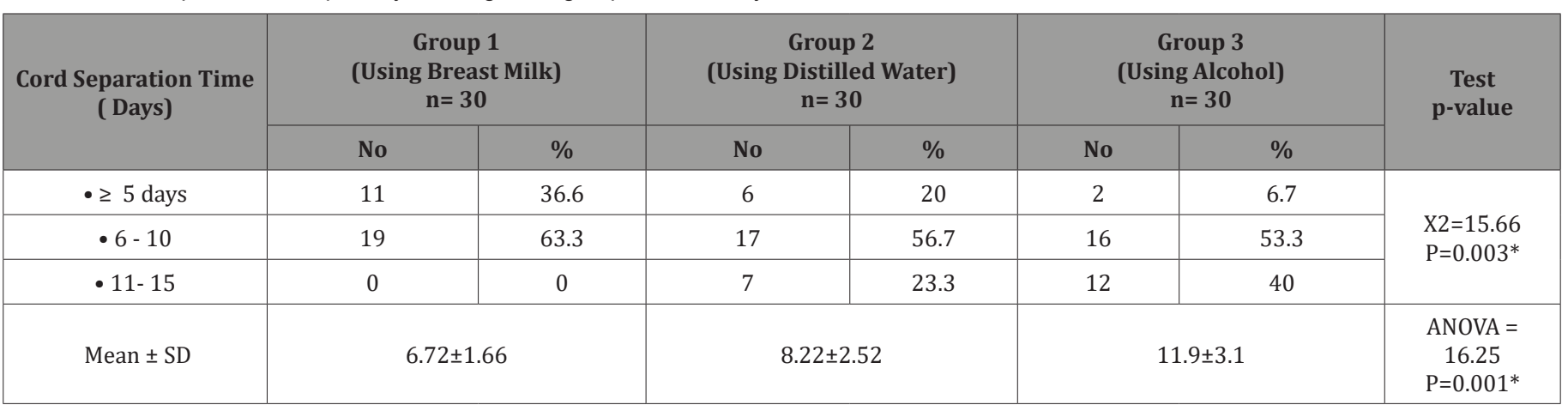

$X^{2}$ : Chi-Square test ${ }^{*}$; Statistically significant at $p \leq 0.05$.

Cord separation time per day among three groups was given away in Table 3. More than one third (36.6\%) of neonates of group 1 and approximately one quarter (20\%) of neonates in group 2 compared to only $6.7 \%$ of neonates in group 3 complete time of umbilical cord separation at 5 or less than 5 days of age.
A statistically significant difference was revealed between groups (ANOVA $=16.25, \mathrm{P}=0.001$ ) was observed and the mean time of cord separation per day among three groups was $6.72 \pm 1.66,8.22 \pm 2.52$ and $11.9 \pm 3.1$ respectively.

Table 4: Cord bleeding and mucouid secretion time after cord separation among the 3 groups of the study.

\begin{tabular}{|c|c|c|c|c|}
\hline Variable & $\begin{array}{c}\text { Group 1 } \\
\text { (Using Breast Milk) } \\
\mathbf{n = 3 0}\end{array}$ & $\begin{array}{c}\text { Group 2 } \\
\text { (Using Distilled Water) } \\
\mathbf{n = 3 0}\end{array}$ & $\begin{array}{c}\text { Group 3 } \\
\text { (Using Alcohol) } \\
\mathbf{n = 3 0}\end{array}$ & $\begin{array}{c}\text { ANOVA Test } \\
\mathbf{p} \text {-value }\end{array}$ \\
\hline $\begin{array}{c}\text { Bleeding continuation after separation } \\
\text { (day) }\end{array}$ & $1.29 \pm 0.44$ & $3.88 \pm 1.61$ & $4.11 \pm 2.11$ & 12.65 \\
\hline Muocouid secretion after separation (day) & $1.98 \pm 0.87$ & $2.11 \pm 0.89$ & $3.11 \pm 0.89$ & 2.51 \\
\hline
\end{tabular}

*: Statistically significant at $p \leq 0$.

Table 4 interprets cord bleeding and mucouid secretion time after cord separation among the 3 groups of the study. It was found that the mean time of cord separation bleeding / day among three groups was $1.29 \pm 0.44,3.88 \pm 1.61$ and $4.11 \pm 2.11$ respectively. A statistically significant difference between groups was observed $($ ANOVA $=12.65, p=0.001)$. There was no significant difference concerning mucouid secretion after separation in groups.

Table 5: Neonates' distribution along with presence of umbilical cord infection.

\begin{tabular}{|c|c|c|c|c|c|c|c|}
\hline \multirow{2}{*}{ \#Umbilical cord infection } & \multicolumn{2}{|c|}{$\begin{array}{c}\text { Group 1 } \\
\text { (Using Breast Milk) } \\
\mathrm{n}=\mathbf{3 0}\end{array}$} & \multicolumn{2}{|c|}{$\begin{array}{c}\text { Group } 2 \\
\text { (Using Distilled Water) } \\
\mathbf{n = 3 0}\end{array}$} & \multicolumn{2}{|c|}{$\begin{array}{c}\text { Group 3 } \\
\text { (Using Alcohol) } n=30\end{array}$} & \multirow[t]{2}{*}{$\begin{array}{c}\text { Chi Square Test } \\
\text { p-value }\end{array}$} \\
\hline & NO & $\%$ & NO & $\%$ & NO & $\%$ & \\
\hline $\begin{array}{l}\text { No } \\
\text { Yes }\end{array}$ & $\begin{array}{c}28 \\
2\end{array}$ & $\begin{array}{c}93.3 \\
6.7\end{array}$ & $\begin{array}{c}27 \\
3\end{array}$ & $\begin{array}{l}90 \\
10\end{array}$ & $\begin{array}{c}23 \\
7\end{array}$ & $\begin{array}{l}76.7 \\
23.3\end{array}$ & $\begin{array}{c}\chi 2=1.998 \\
p=0.368\end{array}$ \\
\hline
\end{tabular}

₹ Signs of umbilical cord infection include redness around the area, a foul odor, and discharge, or discomfort when touch the area around the umbilical cord.

$X^{2}$ : Chi-Square test*; Statistically significant at $p \leq 0.05$.

Tables 5 clarify the majority $(93.3 \%, 90 \%$, and $76.7 \%$ respectively) of neonates among the 3 groups didn't have any signs of umbilical cord infection. No statistically significant difference was observed among groups $\left(\mathrm{x}^{2}=1.998, \mathrm{P}=0.368\right)$.

\section{Discussion}

A neonate is precious not only to his/her parents and family, but child is the foundation of the health \& wealth of community \& nation. Henceforward the health of children is not only desired but 
positively valued by every society and improved level of health is the accepted goal of all communities [15]. Cord care is the series of steps applied in handling of the umbilical cord after delivery of the neonate and if not precisely disbursed can contributes considerably to neonates' risk of infection and mortality [16].

Umbilical cord separation (UCS) normally occurs in the first 2 weeks after birth. Delayed UCS, particularly after 1 month, is associated with different complications such as bacterial infection [17]. Consequently, the present study was fulfilled to monitor the effect of topical application of mother breast milk, distilled water and Alcohol on rapidly separation time of umbilical cord stump among neonates. The study groups of mothers in the present study were similar for their characteristics and the majority of them were multiparas. Likewise, there was no significant statistical difference was found among the three groups in neonates' gender, birth weight, type of delivery and maternal age.

Maintaining and expanding education for women will play a critical role in driving continued improvement in health outcomes. It increases their self- reliance, the ability to make health decisions and to seek better health care. Slightly around one third of mothers in the three studied groups at the present study had secondary educational level. This can help for women cooperation, accepting and practicing cord care procedure [18].

Presently, harmful traditional cord-care practices are often cited as an important public health apprehension. A clear understanding of behavioral intention underlying ancient cord care practices in low- and middle-income countries will be useful in addressing high rates of neonatal infection. With this in mind, the impact of poverty on availability of certain resources to care of cord needs to be placed into consideration [19]. In this study, about half of mothers in three groups of study had low socio-economic level and live in rural area. This result is congruent with study conducted in Zambia (2013) [20] which stated that almost half of the study population belonged to lower socioeconomic state. This may ensue to it each country had low financial gain per capita.

Current study revealed that more than half of the mothers in 3 study groups had unsatisfactory level of knowledge about cord care. This finding is inconsistence with study done in Iran (2013) [21] it had found that $78.5 \%$ had moderate, $13.3 \%$ had a good knowledge \& $8.2 \%$ had poor knowledge regarding newborn care. Another study done by Castalino et al. [22] states majority of mothers had good knowledge concerning cord care.

Regarding sources of knowledge among studied groups of mothers about cord care, the present study discovered that, about two thirds of mothers obtained their knowledge from family members, followed by neighbors or friend then doctors and nurses. It may be attributed to that more than half of mothers in three groups of study subjects were living as a part of an extended family but these results converse with study done in Kenya (2017)[23], which showed that 95.4 percent of women receive antenatal and postnatal care from a medical professional, either from nurses and midwives $(64.3 \%)$ or doctors $(31.1 \%)$. The strangeness of the results may be implying that mothers in those setting rely predominantly on health care providers for information on neonates care rather than family and peers.

The umbilical cord is one of the routes of entry of microorganisms that can cause infection either be localized to the cord (omphalitis) or can spread through the blood stream and become systemic causing neonatal sepsis. Hence, affordable, effective, and safe cord care regimens are needed to prevent from such infections [24,25]. America Academy of Pediatrics quantified that, rubbing alcohol is still routinely used in South Africa as the standard method of caring for the umbilical cord despite many other countries (such as the United Kingdom) terminating the practice due to certain problems it creates. In South Africa, mothers are instructed to apply surgical spirits to the base of the cord with every nappy change, but alternative practices exist. On the other hand, studies have shown that using Surgical Spirits to clean the umbilical cord increase the time it takes for the cord to fall off, and is linked to irritation of the neonate's skin. In some cases, where the alcohol solution has been liberally applied, the neonate has shown signs toxic effects caused by absorption - hemorrhagic skin necrosis, dysfunction of the central nervous system, metabolic acidosis, and hypoglycemia [26].

Multani [27] compared the use of alcohol (70\% isopropyl alcohol) as opposed to distilled water and natural drying for umbilical cord care in a randomized control study $(n=500)$. Umbilical cord separation time ranged from 4-13 days and distilled water seems to be effective in cord healing and reduction in bacterial colonization rates. Likewise, Azzam et al. [28] examined the effect of topical application of alcohol 70\% versus distilled water on umbilical cord stump separation time they reported that, separation time of umbilical cord stump occurred early for neonates in the alcohol group vs. neonates in the distilled water group $(6.70+$ 1.03 days $\& 7.92+1.08$ days respectively).

Recently, four large community-based randomized trials have been conducted in Nepal [29], Pakistan [30], Bangladesh [31] and Sudan [32] to study the effectiveness of application of $4.0 \%$ chlorhexidine to the umbilical cord after birth; all 4 South Asian trials showed fairly similar, statistically significant effects against mortality with reduction rates ranging from $6 \%$ to $38 \%$.

Internationally, World Health Organization (WHO) has advocated since 1998 for the use of dry umbilical cord care (keeping the cord clean with water without application of anything and leaving it exposed to air or loosely covered by a clean cloth) [33-35].

Analogous to these results, Zupan et al. [36] performed a metaanalysis of twenty-one studies involving 8959 participants to assess the effects of topical cord care in preventing cord infection, illness and death. The researchers found that there have been no benefits in terms of the use of antibiotics or antiseptics over merely keeping point cords clean and dry.

In a similar randomized controlled trial study done in Iran (2006) [37] researchers showed that the cord separation time in triple dye group was significantly longer than in dry cord care group, while there was no significant statistical difference between alcohol group and dry cord care group. 
Human breast milk was applied on the cord that reduced microorganism settlement and rope separation time. Human milk contains large amounts of IgA antibodies which can improve the immunity of neonates. [38]. It promotes growth and repair of musculoskeletal system. The presence of polymorph nuclear leukocytes and other immunologic compounds in the breast milk can decrease the process of cord separation. Colostrum contains a large amount of natural antimicrobial agents and can provide specific and nonspecific passive immunity to the neonates [39].

Present study publicized that human milk significantly accelerates the cord separation where more than one third of neonates that use human breast milk complete time of umbilical cord separation at 5 or less than 5 days of age, approximately one quarter $(20 \%)$ of neonates using distilled water compared to only $6.7 \%$ for neonates using alcohol application. The mean time of cord separation / day among three groups was $6.72 \pm 1.66,8.22 \pm 2.52$ and $11.9 \pm 3.1$ respectively with significant differences among groups. The findings of the present study are congruent with, Yonis (2010) [40] who reported that, umbilical cord stump separation time in human milk group was shorter than in the alcohol group (4+1 \& 8+2 days respectively).

Additionally, this result is matched with study done in Egypt (2011) which compared the effect of topical application of breast milk versus distilled water on umbilical cord stump separation time and occurrence of bacterial colonization among neonates. They reported that separation occurred early for neonates in the breast milk group Vs neonates with distilled water group $(5.60+1.04$ days $\& 7.92+1.08$ days respectively) [26]. Moreover, parallel results of study done in Egypt (2016) [41] reported that cord separation was faster in the human milk neonates than in the alcohol group. In this regard, almost half of human milk group neonates had their cord fallen off at the 3rd-4th day of age and (46\%) of them had their cord fallen off at the 5th-6th day of age. On the other hand, $22 \%$ of the neonates in the alcohol group had their cord fallen off at the 5th6th day. But in discrepancy of this result another study reported that the majority of the human milk-treated group (74\%) had their cord fall off at the 6th-10th day which was longer than the duration described in current study. The variance in cord separation time for human milk group could be attributed to differences in the number of the study subjects and/or the study settings [42].

In this view, the study presented that the duration of the umbilical cord stump separation time in breast milk group is shorter than in the group use distilled water and natural dry by about two days. In spit the umbilical cords were detached in each group among the traditional amount between (5-15 days following the birth) as documented in literatures. This result is matched with Golshan \& Hossein [43], they specified that the mean of umbilical separation time had significant differences among the three groups ( $p<0.0001)$. The lowest and the highest separation times belonged to human milk and ethanol groups respectively and similar to study done by Dhanawade [44] who recommended that the total mean score of breast milk application group after intervention was 5.22 and in control group 9.36 the research hypothese (H1) was accepted as breast milk application is highly effective in the early separation of cord stump.

Furthermore, the present study showed that there was statistically significant difference between mother breast milk topical group and group using distilled water care where the bleeding continuation after cord separation (day) was significantly shorter $(\mathrm{p}<0.001)$ among breast milk group than group 2 who used water for cord care. There was no significant difference concerning moucouid secretion after separation in both groups

It is evident from results of current study that the low percentage $6.7 \%$ to $10 \%$ of neonates in the breast milk and distilled water groups respectively had hotness and mild redness only but nearly one quarter of neonates using alcohol in group 3 had signs of umbilical cord stump infection. This might be due to high efficacy of breast milk and distilled water in reducing the signs of umbilical cord stump infection. This finding is in accordance with the research findings of Azzam et al. [26] who conveyed that no statistical significance difference between groups was found regarding to signs of infection however the neonates in the alcohol cord care group had more redness around their umbilical cord stump than in the dry cord care group and this may be due to the alcohol absorption and its effect on the neonatal skin.

In the same field, study done in Egypt (2015) [45] stated that the majority of neonates in the breast milk and dry cord groups had normal bacterial colonization where $95 \%$ and $94 \%$ of them respectively developed normal Staphylococcus epidermis. Low percentage $5 \%$ to $6 \%$ of neonates in the breast milk and dry cord groups had hotness and mild redness. Pathogenic organism, only2\% in the breast milk group developed Escherichia coli and Staphylococcus aureus as compared to $2 \%$ and $4 \%$ in dry cord group. This in disagreement with Farahani et al. [46] who testified occurrence of bacterial colonization between breast milk group and dry cord care group and reported high percentage of pathogenic organisms was found in the dry cord care group.

Umbilical cord care practices for neonates vary between health care settings which can lead to misunderstanding for both parents and nurses. It seems that the current standard of umbilical cord care may be based on historic practices and traditions rather than on scientific investigation and justification. So, application to the umbilical cord stump can make the health care workers, specially nurses and doctors aware of it. So that it may be used by all settings for the profit of neonates.

Breast milk with its antimicrobial properties acts as a defensive agent protecting the cord from getting infected as the neonates has no protective flora at birth. Over and above this breast milk is also having influence over falling of umbilical cord causing early separation thereby decreasing the exposure to environment resulting in less chances of infection. Hoping the findings of the present study leads to avoid the gap between research studies and clinical practice and to deliver practical evidence to inform policy on the implementation of sustainable interventions in neonatal units to decrease neonatal mortality [47]. 


\section{Conclusion \& Recommendations}

It was apparent from the findings that the study hypothesis was accepted and supported where the intervention of breast milk application was significantly effective for early separation of the cord and when compared together with another application, it was found that there was highly significant difference among the breast milk application group. Therefore, the study recommended that: - topical application of mother milk on the remaining part of the cord reduces the cord separation time as compared even with distilled water cord care and it can be used as an easy and cheap way for cord care. Additional researches are proposed to confirm the results and to evaluate the effect of the implementation of these methods on improvement of the umbilical cord care.

\section{Acknowledgement}

The authors would like to offer their sincere thanks to all mothers who participated in this study. Also, the study would not have been possible without the co-operation of the director of the national medical institute in Damanhour governorate and staff members of post-partum department.

\section{References}

1. Gallina L, Tina A, Basso T, Brusaferro S, Quattrin R (2016) Umbilical Cord Care After the First Day From Birth: A Case Control Study in a Northeastern Italian Hospital. Pediatrics and neonatal nursing 3(1): 4-9.

2. Abbaszadeh F, Hajizadeh Z, Jahangiri M (2016) Comparing the impact of topical application of human milk and chlorhexidine on cord separation time in newborns. Pak J Med Sci 32(1): 239-243.

3. Karumbi J, Mulaku M, Aluvaala J, English M, Opiyo N (2013) Topical umbilical cord care for prevention of infection and neonatal mortality. Pediatr Infect Dis J 32: 78-83.

4. Habibi M, Mahyar A, Heidari R, Javadi A, Mahyar S (2014) Eau de Dalibour vs. Alcohol for Umbilical Cord Care. Journal of tropical pediatrics 60(4): 292-296.

5. Bhatt B, Malik JS, Jindal H, Sahoo S, Sangwan KA (2015) A study to assess cord care practices among mothers of new borns in urban areas of Rohtak Haryana. Int J Basic Appl Med Sci 5(1): 55-60.

6. Broom MA, Smith SL (2012) Late Presentation of Neonatal Omphalitis Following dry Cord, Care. Clinical Pediatrics 52(7): 675-677.

7. Lawn JE, Kerber K, Enweronu-Laryea C, Cousens S (2010) 3.6 million neonatal deaths-what is progressing and what is not? Semin Perinatol 34(6): 371-386.

8. Martins RJ, Fanaroff AA, Walsh MC, Edwards MS (2011) postnatal bacterial infections. In Neonatal-Perinatal Medicine: Diseases of the Fetus and Infant. $9^{\text {th }}$ edn, Elsevier, St Louis, USA, pp. 793-829.

9. Liu MF, Lee TY, Kuo YL, Lien MC (2012) Comparative effects of using alcohol, natural drying and salicylic sugar powder on umbilical stump detachment of neonates. J Perinat Neonatal Nurs 26(3): 269-274.

10. World Health Organization (2013) Recommendations on Postnatal Care of the Mother and Newborn. Who Reproductive Health Library.

11. Chawla G, Diwaka KK (2015) Comparison of Umbilical Cord Cleansing Using Sterile Water and Povidine Iodine-Spirit During Early Neonatal Period: A Double Blind Randomized Control Trial. J Clin Diagn Res 9(7): SC01-SC03.

12. Monebenimp F, Enganemben MM, Chelo D, Foumane P, Kamta C, Kuaban C (2013) Mothers' knowledge and practice on essential newborn care at health facilities in Garoua city, Cameroon. Health Sci Dis 14(2): 1-6.

13. Abbaszadeh F, Hajizadeh Z, Seraji P , Sadat Z (2018) Comparing the impacts of topical chlorhexidine and dry cord care on umbilical cord separation time among neonates. Nursing and Midwifery Studies 7(2): 62-66.

14. Fahmy SI, El-Sherbini AF (1983) Determining simple parameters for social classifications for health. Bull High Inst Public Health. 13(5): 95108.

15. Hamina D, Kever RT, Njida NU, Nelson L, Haruna H, et al. (2018) Survey of umbilical cord care practices and separation time in healthy new-born in Maiduguri. Nigeria Clinical Nursing Studies 6(4).

16. Guen GL, Caille A, Launay E, Boscher C, Godon N, et al. (2017) Dry Care Versus Antiseptics for Umbilical Cord Care: A Cluster Randomized Trial. Pediatrics 139(1).

17. Broom MA, Smith SL (2012) Late Presentation of Neonatal Omphalitis Following Dry Cord, Care. Clinical Pediatrics 52(7): 675-677.

18. Zahra K, Zahra A, Saber MA, Dehnavi ZM (2018) The effect of small group teaching on quality of life in pregnant women with nausea and vomiting: A clinical trial J Edu Health Promot 7: 112.

19. Coffey PS, Brown SC (2017) Umbilical cord-care practices in lowand middle-income countries: a systematic review. BMC Pregnancy Childbirth; 17(1): 68.

20. Herlihy JM, Shaikh A, Mazimba A, Gagne N, Grogan C, et al. (2013) Local perceptions, cultural beliefs and practices that shape umbilical cord care: a qualitative study in Southern Province, Zambia. PLoS One 8(11).

21. Reza S, Hassan E (2013) Knowledge assessment of neonatal care among postnatal mothers. Iranian Journal of Neonatology 4(1): 28-31.

22. Castalino F, Nayak B, Souza A (2014) Knowledge and practices of postnatal mothers on newborn care in Tertiary Care Hospital of Udupi District. Nitte .University Journal of Health Science 4: 98-101.

23. Amolo L, Irimu G, Njai D (2017) Knowledge of postnatal mothers on essential newborn care practices at the Kenyatta National Hospital: a cross sectional study Pan Afr Med J 28: 97.

24. Lyngdoh D, Kaur S, Kumar P, Gautam V, Ghai S (2018) Effect of topical application of human breast milk versus $4 \%$ chlorhexidine versus dry cord care on bacterial colonization and clinical outcomes of umbilical cord in preterm newborns. Journal of Neonatal Nursing 7( 1) : 25-30.

25. Mir F, Tikmani SS, Shakoor S, Sultana S, Ali SA, et al. (2011) Incidence and etiology of omphalitis in Pakistan: a community-based cohort study. J Infect Dev Ctries 5(12): 828-833.

26. America Academy of Pediatrics (2016) Umbilical Cord Care.

27. Multani KS (2006) Randomized control study of umbilical cord care at birth. Unpublished dissertation submitted to Rajiv Gandhi University of Health Sciences, Bangalore, India.

28. Azzam H, Abd El Hamid A, Abd El Fadil N (2011) Effect of topical application of alcohol $70 \%$ versus distilled water on umbilical cord stump separation time and bacterial colonization among neonates at $\mathrm{El}$ Manial Maternity Hospital-Cairo University: randomized control trial. Egyptian Nursing Journal 1(2).

29. Mullany LC, Darmstadt GL, Khatry Lancet SK (2006) Topical applications of chlorhexidine to the umbilical cord for prevention of omphalitis and neonatal mortality in southern Nepal: a community-based, clusterrandomized trial 367(9514): 910-918.

30. Soofi S, Cousens S (2012) A Topical application of chlorhexidine to neonatal umbilical cords for prevention of omphalitis and neonatal mortality in a rural district of Pakistan: a community-based, clusterrandomized trial Imdad Lancet 379(9820): 1029-1036.

31. Arifeen SE, Mullany LC, Shah Lancet R (2012) the effect of cord cleansing with chlorhexidine on neonatal mortality in rural Bangladesh: a community-based, cluster-randomized trial 379(9820): 1022-1028.

32. Abdelmoneim EM, Kheir Amna MA, Mustafa AO (2015) Impact of Umbilical Cord Cleansing with $4 \%$ Chlorhexidine on Rate of Omphalitis and Separation Time Among Newborns in Khartoum State, Sudan 3(1).

33. World Health Organization (2013) Postnatal Care of the Mother and Newborn. 
34. Karumbi J, Mulaku M, Aluvaala J, English M, Opiyo N, et al. (2013) Topical umbilical cord care for prevention of infection and neonatal mortality. Pediatr Infect Dis J 32:78-83.

35. Quattrin R, Iacobucci K, Anna Lisa De Tina A, Gallina L, Pittini C, et al. (2016) 70\% Alcohol Versus Dry Cord Care in the Umbilical Cord Care A Case-Control Study in Italy. Medicine (Baltimore) 95(14).

36. Zupan J, Garner P, Omari A (2004) Topical umbilical cord care at birth. Cochrane Database of Systematic Reviews (3).

37. Ahmadpour MK, Zahedpasha Y, Hajian K, Javadi G, Talebian H, et al. (2006) The effect of topical application of human milk ethyl alcohol 96\%, and silver sulfadiazine on umbilical cord separation time in newborn infant. Arch Iran Med 9(1): 33-38.

38. Allam N, Al Megren W, Talat A (2015) the effect of topical application of mother milk on separation of umbilical cord for newborn babies. Am J Nurs Sci 4: 288-296.

39. Abbaszadeh F, Hajizadeh Z, Atrian M, Bagheri A, Sarafraz N (2014) Comparison of the effect of topical application of human milk and dry cord care on the bacterial colonization of umbilical cord in newborn infants. J Kermanshah Univ Med Sci 18: 1-8.

40. Yonis ES (2010) The effect of topical application of human milk comparable with $70 \%$ ethyl Alcohol on umbilical cord separation time in newborn infant at Minia University Hospital. Unpublished thesis.
41. Mahrous E, Darwish M, Dabash S, Ibrahim M, Abdelwahab S (2012) Topical application of human milk reduces umbilical cord separation time and bacterial colonization compared to ethanol in newborns. Translational Biomedicine 3(1): 4.

42. Vural, G ,Kisa, S (2006) Umbilical cord care: a pilot study comparing topical human milk, povidone-iodine, and dry care. J Obstet Gynecol Neonatal Nurs 35(1): 123-128.

43. Golshan M, Hossein N (2013) Impact of ethanol, dry care and human milk on the time for umbilical cord separation. J Pak Med Assoc 63(9): 1117-1119.

44. Dhanawade RA (2014) Innovations in Pharmaceuticals and Pharmacotherapy. IPP 2(3): 386- 394.

45. Allam N, AL Megrin W, Talat A (2015) The Effect of Topical Application of Mother Milk on Separation of Umbilical Cord for Newborn Babies. American Journal of Nursing Sciencen 4 (5): 288-296.

46. Farahani L, Mohammadzadeh A, Tafazzoli M ,Esmaeli H, Ghazvini K (2008) Effect of topical application of breast milk and dry cord care on bacterial colonization and umbilical cord separation time in neonates. Journal of Chinese Clinical Medicine 3(6): 327-332.

47. Aghamohammadi A, Zafari M , Moslemi L (2012) Comparing the Effect of Topical Application of Human Milk and Dry Cord Care on Umbilical Cord Separation Time in Healthy Newborn Infants Iran J Pediatr 22(2): 158- 162. 